\title{
Comparison of Sapwood Discoloration in Fagaceae Trees After Inoculation with Isolates of Raffaelea quercivora, Cause of Mass Mortality of Japanese Oak Trees
}

Dai Kusumoto, The University of Tokyo Tanashi Forest, Graduate School of Agricultural and Life Sciences, the University of Tokyo, 1-1-8 Midori-cho, Nishi-tokyo, Tokyo 188-0002; Hayato Masuya, Tohoku Research Center, Forestry and Forest Products Research Institute, 92-25 Nabeyashiki, Shimokuriyagawa, Morioka, Iwate 020-0123, Japan; Toshihide Hirao, The University of Tokyo Chichibu Forest, Graduate School of Agricultural and Life Sciences, the University of Tokyo, 1-1-49 Hinoda-machi, Chichibu, Saitama 368-0034, Japan; Hideaki Goto, Kyushu Research Center, Forestry and Forest Products Research Institute, 4-11-6 Kurokami, Chuo-ku, Kumamoto 860-0862, Japan; Keiko Hamaguchi, Kansai Research Center, Forestry and Forest Products Research Institute, 68 Nagaikyutaro, Fushimi-ku, Kyoto 612-0855, Japan; Wen-I Chou, Department of Life Science, National Taitung University, No. 684, Sec. 1, ZhongHua Rd., Taitung 95002, Taiwan; Wiwat Suasa-ard, Department of Entomology, Kasetsart University, KamphaengSaen, Nakhon Pathom 73140, Thailand; Sawai Buranapanichpan, Faculty of Agriculture, Chiang Mai University. Chiang Mai 50200, Thailand; Sopon Uraichuen, Oraphan Kern-asa, and Sunisa Sanguansub, Department of Entomology, Kasetsart University; Aumporn Panmongkol, Doi Suthep-Pui National Park Office, Chiang Mai 50200, Thailand; Quang Thu Pham, Vietnamese Academy of Forest Science, Dong Ngac, Tu Liem, Hanoi, Vietnam; Sih Kahono, Museum Zoologicum Bogoriense, Division of Zoology, and I Made Sudiana, Microbiology Division, Research Center for Biology, LIPI, JL. Raya Jakarta-Bogor Km.46, Cibinong, Bogor 16911, Indonesia; and Naoto Kamata, The University of Tokyo Chichibu Forest, Graduate School of Agricultural and Life Sciences, the University of Tokyo

\begin{abstract}
Kusumoto, D., Masuya, H., Hirao, T., Goto, H., Hamaguchi, K., Chou, W.-I., Suasa-ard, W., Buranapanichpan, S., Uraichuen, S., Kern-asa, O., Sanguansub, S., Panmongkol, A., Pham, Q. T., Kahono, S., Sudiana, I. M., and Kamata, N. 2015. Comparison of sapwood discoloration in Fagaceae trees after inoculation with isolates of Raffaelea quercivora, cause of mass mortality of Japanese oak trees. Plant Dis. 99:225-230.

The mass mortality of oak trees has been prevalent in Japan since the late 1980s. The fungus Raffaelea quercivora is transmitted by an ambrosia beetle, Platypus quercivorus, which causes mortality. The beetle is able to bore galleries into the sapwood of most Fagaceae trees in Japan; however, the level of mortality caused by $R$. quercivora and $P$. quercivorus differs greatly among tree species. Previous studies by our research group have demonstrated that the virulence of $R$. quercivora differs among isolates when inoculated into Quercus serrata logs. However, interactions between the virulence of $R$. quercivora isolates and the susceptibility of other fagaceous species have yet to be elucidated. In this study, we inoculated the fresh logs of 11 fagaceous species with isolates of low and high virulence, and measured the tangen-

tial widths of discolored sapwoods 3 weeks after inoculation. Although the discoloration widths of $Q$. crispula sapwood were similar among all isolates, those of $Q$. serrata and $Q$. acutissima tended to increase with the more virulent isolates. Sapwood discoloration in $Q$. glauca, $Q$. acuta, Q. salicina, Lethocarpus edulis, and Castanopsis sieboldii was greatly increased by highly virulent isolates. Discoloration in Fagus japonica was not influenced by any of the isolates. The logs of $Q$. crispula and $Q$. serrata but not $Q$. glauca were significantly more discolored by a low-virulence isolate compared with standing trees. The various virulent isolates induced unique sapwood discoloration characteristics in each species, which may explain species-specific differences in mortality rates.
\end{abstract}

Over the last 20 years, fungi carried by ambrosia beetles have caused the mass mortality and dieback of woody plants worldwide, threatening their survival. Examples include laurel wilt in the United States (2) and Fusarium dieback in Israel and the United States $(1,3)$, along with the mass mortality of oak trees in Korea (7) and Japan (5). Consequently, these pathogens have had major ecological and economic impacts on the forests and orchards of many of the regions of the world.

The mass mortality of oak trees has been prevalent in Japan since the late 1980 s, with the range in mortality continuing to expand. Causal agents of this mortality are the ambrosia beetle Platypus quercivorus (Murayama) and the associated fungus Raffaelea quercivora Kubono et Shin. Ito (13). Mortality caused by P. quercivorus was first reported in 1934 (5). Subsequently, outbreaks

Corresponding author: D. Kusumoto,

E-mail: kusumoto@uf.a.u-tokyo.ac.jp

* The $\boldsymbol{e}$-Xtra logo stands for "electronic extra" and indicates that one supplementary table and two supplementary figures are available online.

Accepted for publication 5 August 2014.

http://dx.doi.org/10.1094/PDIS-06-14-0581-RE

(C) 2015 The American Phytopathological Society occurred intermittently in restricted areas, primarily in stands that were over 40 years old (5). Each outbreak lasted a few years, with intervals of several decades between outbreaks until the mid1980s. Moreover, documents dating back to 1790 in Nagano Prefecture recorded similar damage of oak trees in a shrine forest (4). From the features of incidence before the mid-1980s, $P$. quercivorus has been considered to be a native species in Japan. Two reasonable hypotheses for the recent epidemic have been proposed. The first hypothesis is an increase in the size and age of oak trees in abandoned coppice forests, which are preferable for the reproduction of beetles (12). The second hypothesis is global warming, which potentially shifts the distribution of beetles to more northerly latitudes and higher altitudes (6).

In early summer, $P$. quercivorus attacks the trunks of living oak trees and bores galleries into the sapwood. The female beetle has mycangia in the pronotum (8) and, thus, introduces $R$. quercivora into the galleries during its boring activities (9). Introduced $R$. quercivora induces sapwood discoloration, along with the loss of water conductance around the galleries $(14,15)$. Consequently, the oak trees wilt and die when the ascent of sap is completely blocked at any cross-section of the trunk. Because sapwood discoloration induced by $R$. quercivora is limited to a narrow area around the galleries (34), mass attacks by $P$. quercivorus are required to kill oak trees (9).

$P$. quercivorus and $R$. quercivora cause different levels of mortality among the Fagaceae species. Quercus crispula exhibits the 
highest mortality in the field, ranging from 50 to $100 \%$ mortality at the stand level, followed by $Q$. serrata, with mortality ranging from 10 to $60 \%(6,10,22,26,28)$. There are also many records of $P$. quercivorus outbreaks in stands of evergreen oak species such as Quercus, Castanopsis, and Lithocarpus. However, these species exhibit much lower levels of mortality than deciduous oaks such as $Q$. crispula and $Q$. serrata $(19,30,32,33)$. In contrast, dead trees belonging to the genus Fagus have not been found yet, despite these trees being attacked by $P$. quercivorus (12).

The mortality of oak trees depends on complex interactions among the host tree, the ambrosia beetle, and the pathogenic fungus. However, our understanding about tree-fungus interactions remains limited compared with tree-beetle interactions. Murata et al. $(20,21)$ artificially inoculated $R$. quercivora into the seedlings and branches of several Fagaceae species, and found that $Q$. crispula and $Q$. serrata had larger areas of discolored and nonconductive sapwood in transverse sections compared with $Q$. glauca, Castanopsis sieboldii, Lithocarpus edulis, and Fagus crenata. In addition, the authors suggested that the xylem vessel arrangement in fagaceous trees (i.e., ring-, radial-, and diffuse-porous wood) is associated with differences in the tangential spread of sapwood discoloration among host species. Torii et al. (35) found that the hyphae of $R$. quercivora spread farther from the inoculation point in the sapwood of $Q$. crispula than that of $Q$. glauca, and that the different widths of nonconductive sapwoods reflect different hyphal growth between the two host species. These articles indicate that the nonconductive area induced by a single inoculation is correlated with the mortality of each species. Furthermore, Kusumoto et al. $(16,17)$ collected fungal isolates from Japan and other Asian countries and showed that the most virulent isolate caused twice as much discoloration in $Q$. serrata logs than the least virulent isolate.

Although our previous studies have indicated that there is a considerably large difference of virulence among $R$. quercivora isolates, their effect on the discoloration of the other fagaceous species has yet to be elucidated. In the present study, R. quercivora isolates with different levels of virulence were inoculated into the logs of 11 Fagaceae trees to evaluate the relationship between fungal virulence and host susceptibility. In addition, we compared differences in sapwood discoloration between logs and standing trees to confirm the validity of log inoculation. The results of this study are expected to help estimate the contribution of this pathogen to the mortality of oak trees.

\section{Materials and Methods}

Preparation of inocula. The $R$. quercivora isolates were isolated from the body surface of P. quercivorus collected in Japan, Taiwan, Vietnam, Thailand, and Indonesia (Table 1). All of the isolates were prepared as monospore isolates that originated from a conidium, and were identified by the nucleotide sequence of the internal transcribed spacer 2 and D1-D2 large subunit region of nuclear ribosomal DNA. Isolates with different virulence were selected based on the results of previous studies (Table 1) $(16,17)$. Phytosanitary certificates and research permissions were obtained from the governmental authorities in each country (16).

Autoclaved birch toothpicks $(65 \mathrm{~mm}$ in length and $2 \mathrm{~mm}$ in diameter) were incubated with the mycelia of each isolate on $2 \%$ malt extract ager plates for 2 weeks at $25^{\circ} \mathrm{C}$. After incubation, $R$. quercivora-proliferated toothpicks were used as inocula. Autoclaved toothpicks incubated without $R$. quercivora were used as negative controls.

Experiment 1: Inoculation of the logs of six Quercus spp. in 2012. Three individual trees of $Q$. acuta, $Q$. acutissima, $Q$. glauca, $Q$. salicina, and $Q$. serrata were harvested in natural forest stands in the University of Tokyo Chiba Forest (UTCBF) in Chiba Prefecture, Japan on 2 July 2012. Three individual trees of $Q$. crispula were harvested at the University of Tokyo Chichibu Forest (UTCF) in Saitama Prefecture, Japan on 4 July 2012. After harvesting, the trees were cut into five $\operatorname{logs}(50 \mathrm{~cm}$ in length and 10 to $15 \mathrm{~cm}$ in diameter), and both ends of the logs were immediately sealed with paraffin to prevent desiccation from the cross sections.

Log inoculation was carried out on 4 July 2012. Six holes $(2 \mathrm{~cm}$ in depth and $2.7 \mathrm{~mm}$ in diameter) were drilled from six directions at regular intervals along the circumference of the middle part of the individual logs. Five $R$. quercivora isolates (CXP5-2, IP95-1, $\mathrm{nR} 24, \mathrm{Ta} 28$, and Vt42-1) proliferating in the birch toothpicks and a sterilized toothpick were inserted into each of the six holes on each $\log$. The parts of the toothpicks that were sticking out from the log were cut off. The holes were sealed with Parafilm and adhesive tape to prevent the inocula from drying out. Finally, the inoculations were carried out on $15 \mathrm{logs}$ per tree species. The logs were incubated at $25^{\circ} \mathrm{C}$ in darkness. The inoculation and incubation were carried out inside incubators that were set in a laboratory at Kagemori Nursery of the UTCF under a biosecurity guideline by the Plant Protection Law, Ministry of Agriculture, Forestry, and Fisheries, Japan.

The logs were cut across at the inoculation points after a 3-week incubation period. The cross-sections were photographed using a digital camera (PowerShot SX110 IS; Canon). Then, the areas and lengths of the photographed discolored sapwoods were measured using the graphics software package ImageJ (http://rsbweb. nih.gov/ij/). The tangential widths of discoloration from the edge of the inoculation holes were calculated as the average values of the discolored area of the sapwood on the right and left sides of the inoculation hole divided by the radial length of the discolored sapwood where the area was measured.

Experiment 2: Inoculation to the logs of eight Fagaceae species in 2013. Three individual trees of Castanea crenata, Castanopsis sieboldii, L. edulis, $Q$. glauca, and $Q$. serrata were harvested in natural forest stands in the UTCBF. Three individual trees of $F$. japonica and $Q$. crispula were harvested in the UTCF. Three trees of $Q$. phillyraeoides were harvested in the nursery of a commercial gardening company in Sayama City, Saitama Prefecture, Japan. All trees were harvested on 3 July 2013 . Four logs $(50 \mathrm{~cm}$ in length and 10 to $15 \mathrm{~cm}$ in diameter) were obtained from each harvested tree. Both ends of the logs were immediately sealed with paraffin to prevent desiccation from the cross sections.

Log inoculation was conducted on 9 July 2013, following the same procedure as experiment 1 . Finally, 12 repeats of the inoculated $\operatorname{logs}$ were prepared per tree species. After a 3-week incubation period, the tangential widths of the discolored sapwoods were measured. Some logs showed unexpected discoloration as a result of contamination in experiment 2 . In such cases, the data

Table 1. Raffaelea quercivora isolates used for the inoculation experiment on logs and standing trees

\begin{tabular}{lclll}
\hline Isolate number $^{\mathbf{a}}$ & Other number $^{\mathbf{b}}$ & \multicolumn{1}{c}{ Date } & \multicolumn{1}{c}{ Origin $^{\text {Relative virulence }^{\mathbf{c}}}$} \\
\hline G37 & FFPRI411062 & March 2003 & Ibusuki, Kagoshima, Japan & Low \\
nR24 & FFPRI411059 & September 2006 & Kisakata, Akita, Japan & Moderate \\
Rem10 & $\ldots$ & 2 September 2009 & Naruko, Miyagi, Japan & This is the first time using \\
IP95-1 & $\ldots$ & 23 April 2007 & Cibodas, Indonesia & Low \\
Ta28 & $\ldots$ & 14 January 2009 & Chiang Mai, Thailand & Low \\
Vt42-1 & $\ldots$ & 14 October 2010 & Lao Cai, Vietnam & Low \\
CXP5-2 & $\ldots$ & 18 January 2006 & Taitung, Taiwan & High \\
\hline
\end{tabular}

${ }^{a}$ Reference number for cultures by H. Masuya.

${ }^{b}$ FFPRI: culture collection of Forestry \& Forest Products Research Institute, Japan.

${ }^{c}$ Relative virulence is based on Kusumoto et al. (16). 
affected by the contamination were excluded from all subsequent analyses.

Experiment 3: Comparison of discoloration between logs and standing trees. Three logs of $Q$. crispula, $Q$. glauca, and $Q$. serrata were prepared from the same trees used in experiment 2. Eight holes $(2 \mathrm{~cm}$ in depth and $2.7 \mathrm{~mm}$ in diameter) were drilled midway up the individual logs on 9 July 2013 and were distributed at regular intervals around the circumference. Toothpicks of four inocula (G37, nR24, Rem10, and negative control) were inserted into two of eight holes on a single log, respectively. Inoculations were repeated on three $\operatorname{logs}$ of each tree species. The holes were sealed with Parafilm and adhesive tape and the logs were incubated at $25^{\circ} \mathrm{C}$ in darkness. After a 3-week incubation period, the tangential widths of the discolored sapwoods were measured.

A similar inoculation technique was used on standing trees of $Q$. crispula in a natural forest of UTCF on 9 July 2013 and those of $Q$.

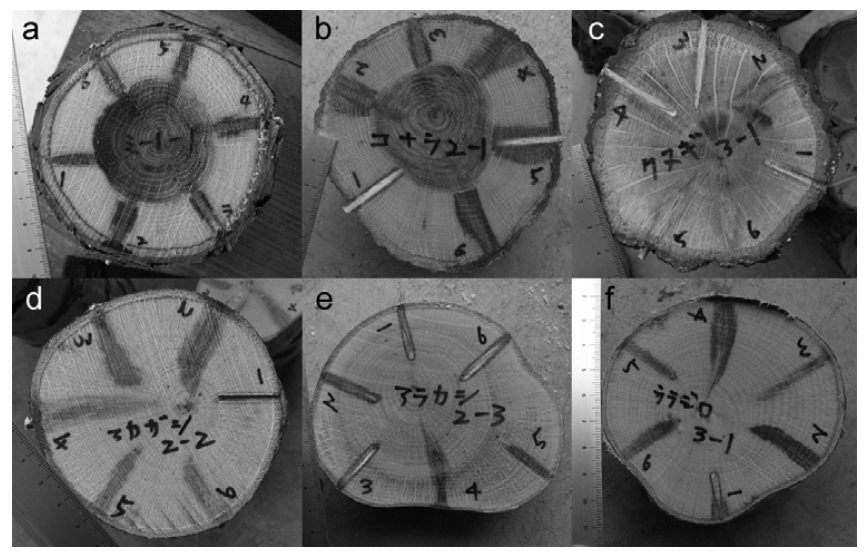

Fig. 1. Cross-sections of the logs of six Quercus spp. near the inoculation points with the Raffaelea quercivora isolates. Numbers beside the inoculation points indicate 1: sterilized toothpick (negative control), 2: nR24, 3: Ta28, 4: CXP5-2, 5: Vt42-1, 6: IP95-1. a, Quercus crispula; b, Q. serrata; c, Q. acutissima; d, Q. glauca; e, $Q$. acuta; f, Q. salicina. glauca and $Q$. serrata in UTCBF on 10 July. Three fungal isolates and a sterilized inoculum were inoculated into the trunks of three standing trees from each species, following the same procedure that was used for the log inoculation. Three weeks later, the trees were harvested and cut across at the inoculation points to measure the extent of sapwood discoloration.

Statistical analysis. The tangential widths of discolored sapwoods were compared among the inocula in each tree species or among the tree species for each inoculum using nonparametric allpair comparisons for joint ranks (Dunn's test). Differences between the logs and the standing trees in experiment 3 were analyzed using Welch's $t$ test. All statistical analyses were conducted using JMP Pro 10 software (SAS Institute Inc.).

\section{Results}

Experiment 1. Photographs of cross-sections near the inoculation points and the boxplots of the tangential widths of the discolored sapwoods from the logs of six tree species belonging to the genus Quercus after the $R$. quercivora inoculations in 2012 are shown in Figures 1 and 2, respectively. The mean tangential widths of the discolored sapwoods caused by nonfungal inoculations (i.e., the negative control) ranged from $0.44 \mathrm{~mm}$ in $Q$. salicina to 1.43 $\mathrm{mm}$ in $Q$. crispula. All $R$. quercivora isolate inoculations significantly increased the discoloration widths of $Q$. crispula compared with the control but there was no significance among the fungal isolates. For $Q$. serrata and Q. acutissima, sapwood discoloration was affected by isolate virulence. The mean widths of the discoloration caused by the most virulent isolate, CXP5-2, were six times as large as those in the control for both species. Inoculation with Ta28, IP95-1, and Vt42-1 slightly increased the discoloration widths (to no more than $2 \mathrm{~mm}$ ) of $Q$. glauca, $Q$. acuta, and $Q$. salicina, while inoculation with $\mathrm{nR} 24$ and CXP5-2 caused large discoloration. Greater variability in discoloration widths was obtained from inoculations with higher virulence isolates, particularly in Q. acutissima.

In comparison with the discoloration widths among host tree species by each inoculum, the discoloration widths in the three deciduous ring-porous species (Q. crispula, $Q$. serrata, and $Q$.

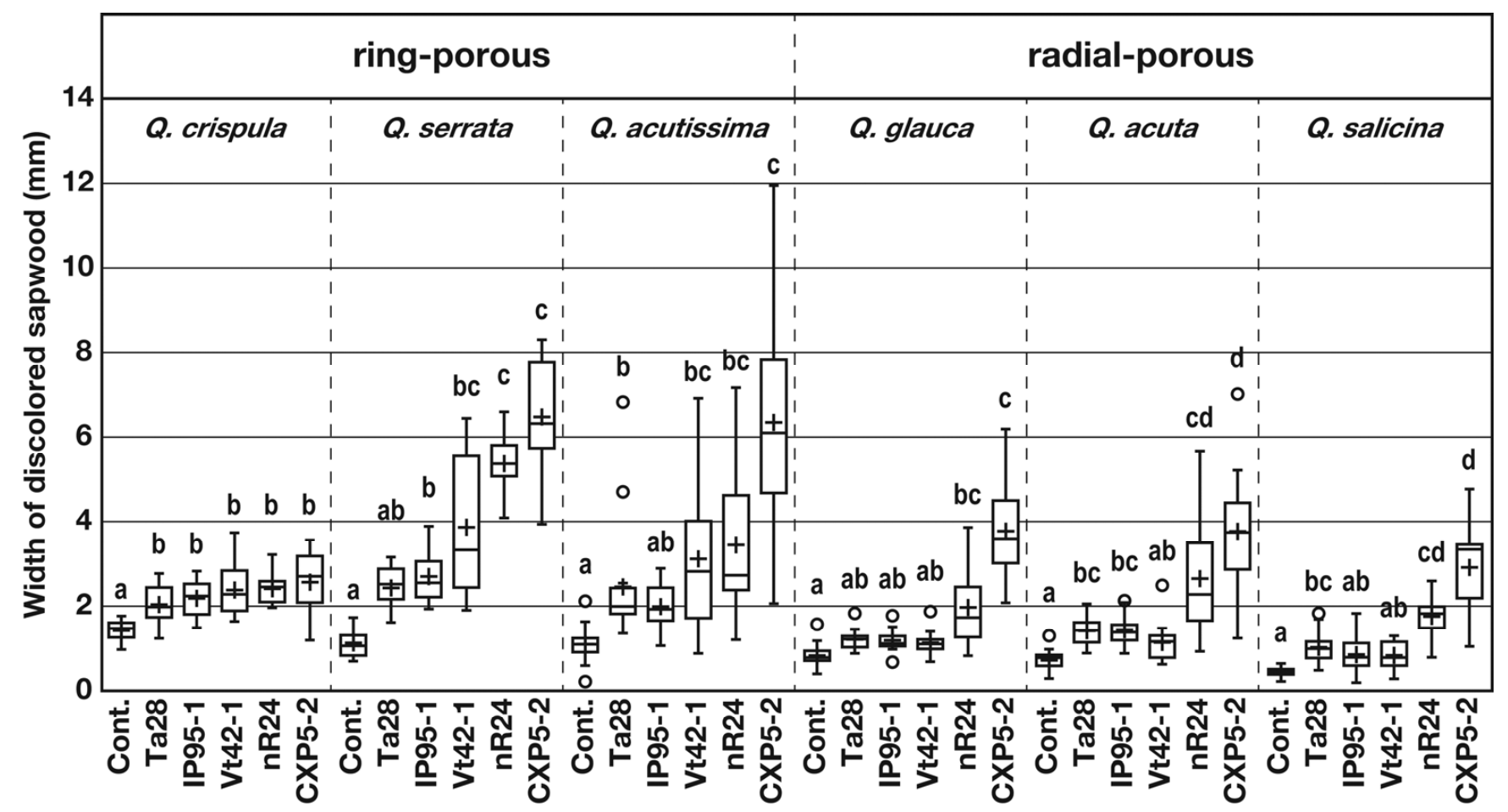

Fig. 2. Boxplots of the tangential widths of the discolored sapwoods from the logs of six Quercus spp. inoculated with low- to high-virulence isolates of Raffaelea quercivora in 2012 (experiment 1). Open circles and plus signs indicate outliers and mean, respectively. Vessel arrangement is indicated as ring-porous or radial-porous. Different letters indicate significant differences among the inocula in each tree species by Dunn's nonparametric test $(P<0.05)$. 
acutissima) were larger than the three evergreen radial-porous species (Q. glauca, Q. acuta, and $Q$. salicina) when Ta28, IP95-1, and Vt42-1 were inoculated (Supplementary Fig. S1). By inoculation with $\mathrm{nR} 24$ and CXP5-2, the discoloration width of $Q$. crispula was similar to the three evergreen radial-porous species.

Experiment 2. Photographs of the cross-sections near the inoculation points and the boxplots of the tangential widths of the discolored sapwoods from the logs of the eight fagaceous species after the R. quercivora inoculations in 2013 are shown in Figures 3 and 4 , respectively. Compared with the control, all isolates greatly increased the discoloration widths of $Q$. serrata. In comparison, the discoloration widths of $Q$. crispula and $Q$. phillyraeoides gradually increased with the virulence of the fungal isolates. In $Q$. glauca, L. edulis, and C. sieboldii, all fungal inoculations (except CXP5-2) caused a slight increase in discoloration width. In contrast, CXP5-2 inoculations induced large discoloration, with great variability, compared with the other isolates. The fungal inocula-

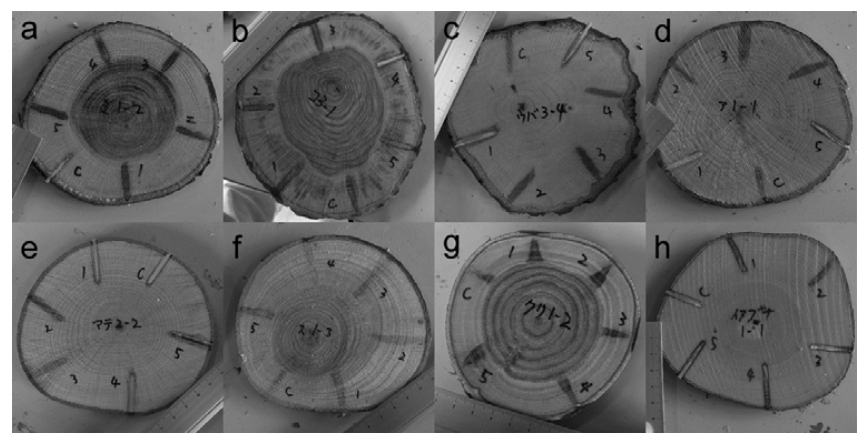

Fig. 3. Cross-sections of the logs of eight Fagaceae species near the inoculation points with the Raffaelea quercivora isolates. A letter and the numbers beside the inoculation points indicate $C$ : sterilized toothpick (negative control), 1: $n R 24,2$ : Ta28, 3: CXP5-2, 4: IP95-1, 5: Vt42-1. a, Quercus crispula; b, Q. serrata; c, Q. phillyraeoides; d, Q. glauca; e, Lithocarpus edulis; f, Castanopsis sieboldii; g, Castanea crenata; $\mathbf{h}$, Fagus japonica. tions increased the discoloration widths of Castanea crenata but the extent of discoloration did not parallel the virulence of the isolates. Of all eight fagaceous species, $F$. japonica was the least discolored by the nonfungal inoculation (negative control) (Supplementary Fig. S2). In addition, the discoloration widths of $F$. japonica were not influenced by any of the isolates, including the isolate with the highest virulence (CXP5-2).

The tangential widths of the discoloration caused by each fungal inoculation in $Q$. crispula and $Q$. serrata were smaller in experiment 2 compared with the corresponding inoculations in experiment 1 . However, the discoloration widths of $Q$. glauca were similar in both experiments.

Experiment 3. The tangential widths of the discolored sapwood in logs and standing trees of $Q$. crispula, $Q$. serrata, and $Q$. glauca induced by the $R$. quercivora inoculations are shown in Figure 5. The tangential widths of discoloration significantly differed in some pair comparisons between the logs and the standing trees inoculated with the same isolates. In the logs of $Q$. crispula and $Q$. serrata, the sterilized inoculum, G37, and Rem10 induced significantly larger discoloration than in the standing trees. In contrast, only the most virulent isolate, Rem 10 , induced significantly larger discoloration in the logs of Q. glauca than in the standing trees.

\section{Discussion}

$Q$. crispula shows the highest mortality by $P$. quercivorus $-R$. quercivora infestation based on field observations. Our results indicated that nonfungal inoculation (sterilized toothpicks) caused $Q$. crispula sapwood to form relatively large areas of discoloration, with fungal inoculations causing greater discoloration. $Q$. serrata and $Q$. acutissima were more sensitive to fungal inoculations than $Q$. crispula, showing the greatest variation in discoloration widths among all isolates. Field-based observations have reported that $Q$. serrata has lower mortality than $Q$. crispula $(6,10,22,26,28)$, and that $Q$. acutissima has lower mortality than $Q$. serrata (27). In the present study, susceptibility based on the size of the discoloration in the three deciduous oak trees did not coincide with the levels of mortality in the field. The mortality of oak trees is related to the

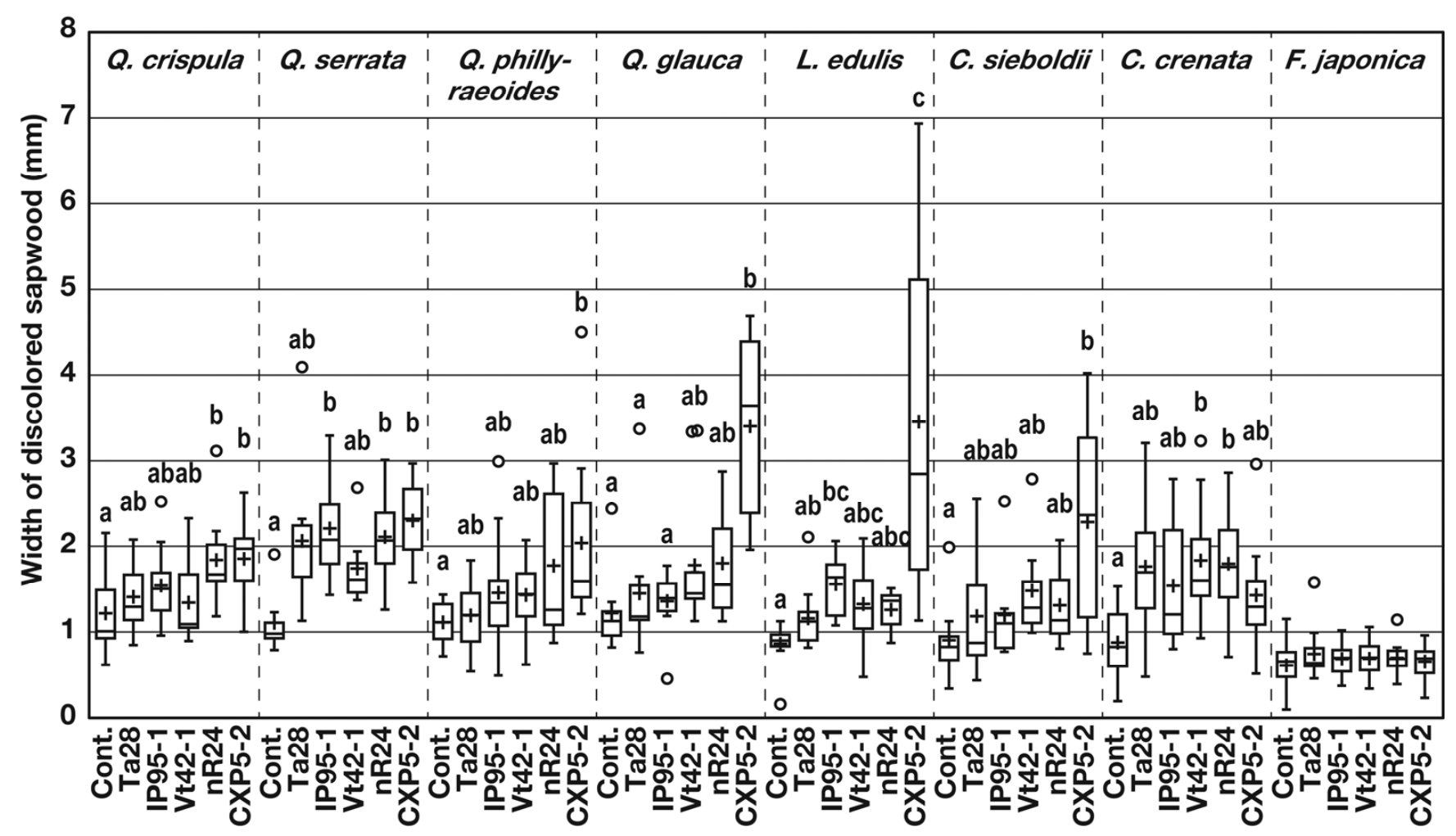

Fig. 4. Boxplots of the tangential widths of the discolored sapwoods from the logs of eight Fagaceae species inoculated with low- to high-virulence isolates of Raffaelea quercivora in 2013 (experiment 2). Open circles and plus signs indicate outliers and mean, respectively. Different letters indicate significant differences among the inocula in each tree species by Dunn's nonparametric test $(P<0.05)$. 
size of discoloration by $R$. quercivora infection, in addition to the density of beetle galleries in the sapwood. Compared with $Q$. crispula, the sap of $Q$. serrata is known to flow more frequently from the holes bored by $P$. quercivorus, which kills boring beetles and reduces beetle reproduction (11). Different levels of morality among $Q$. crispula, $Q$. serrata, and $Q$. acutissima may be more affected by differing levels of susceptibility to beetle infestation rather than their susceptibility to $R$. quercivora infection.

Evergreen radial-porous trees, belonging to the subgenus $C y$ clobalanopsis (genus Quercus) and the genera Lithocarpus and Castanopsis, were minimally affected by the low-virulence isolates. The sapwood discoloration widths of these species were comparatively smaller than the deciduous ring-porous Quercus spp. These differences in discoloration may relate to the lower mortality levels of evergreen oaks in the field, because most $R$. quercivora isolates used in our previous studies were categorized as having low virulence $(16,17)$. In comparison, $Q$. phillyraeoides has evergreen leaves and radial-porous wood, like $Q$. glauca, $L$. edulis, and Castanopsis sieboldii; yet, this species responded in a similar manner to $Q$. crispula.

The tangential width of sapwood discoloration induced by the low-virulence isolates (Ta28, IP95-1, and Vt42-1) in the Castanea crenata logs was relatively large compared with the other species.

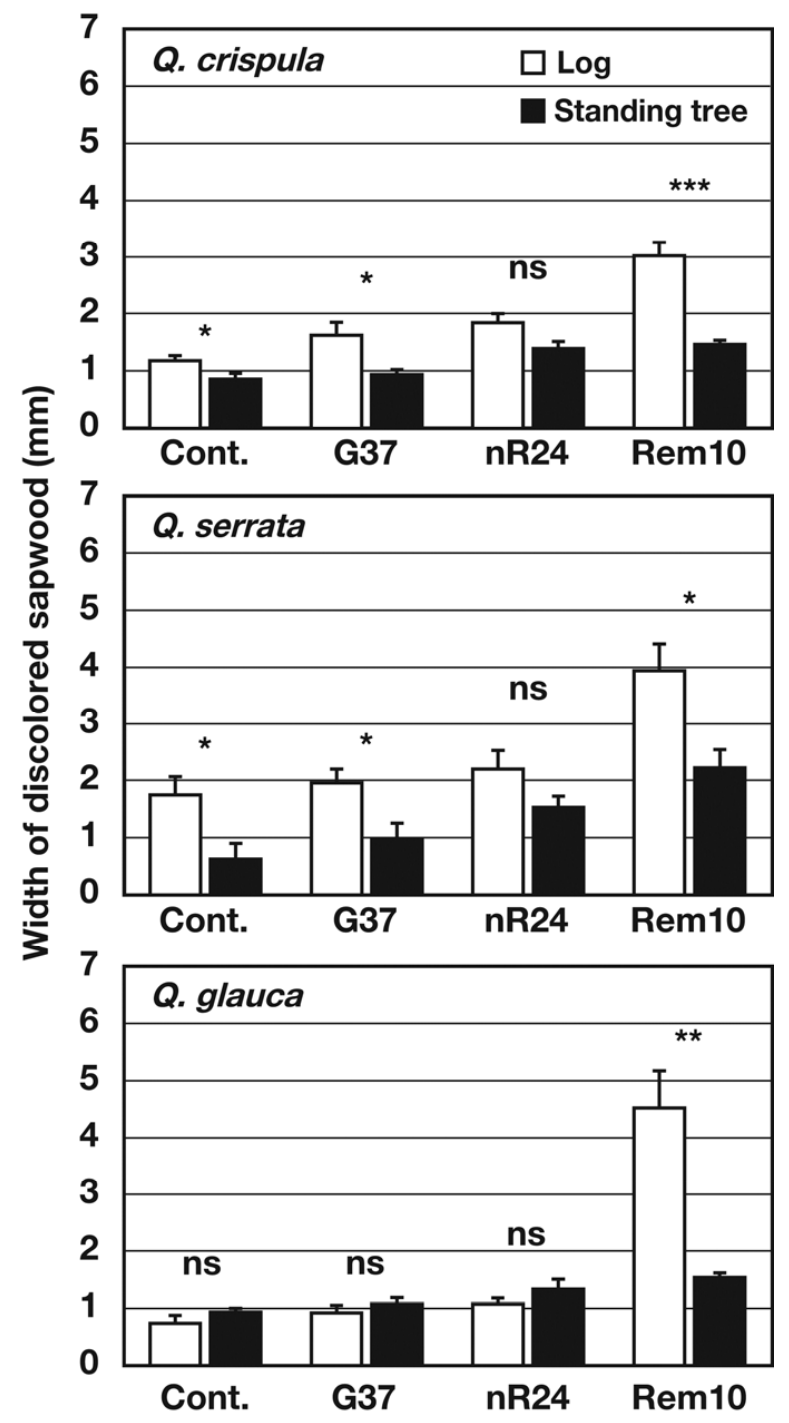

Fig. 5. Mean ( \pm standard error) tangential widths of the discolored sapwoods from the logs and standing trees of three Quercus spp. inoculated with low- to highvirulence isolates of Raffaelea quercivora (experiment 3 ); ${ }^{*},{ }^{* *}$, and ${ }^{* * *}$ indicate significant differences between the logs and standing trees at $P<0.05,0.01$, and 0.001 , respectively, by Welch's $t$ test; ns indicates no significant difference.
However, the shape of discoloration differed from that of the other species (i.e., the discoloration was very narrow near the cambium, and tended to widen toward the heartwood; Fig. 3). In ring-porous trees, including $C$. crenata, water ascent mainly occurs in a current annual ring (31). Therefore, the loss of water conductance induced by $R$. quercivora infection is probably limited in $C$. crenata.

$F$. japonica showed the least sapwood discoloration of all eight fagaceous species in response to all of the inoculations in experiment 2 . In addition, the discoloration widths induced by $R$. quercivora inoculations were similar to those of the nonfungal inoculation. This result may explain why trees belonging to the Fagus genus are not killed by $P$. quercivorus infestations.

The physiological status of a host tree is assumed to be a very important factor in its susceptibility to pathogenic infection (36). In experiment 3, the sapwood discoloration widths of logs were significantly larger than those of standing trees in some comparisons. This result suggests that physiological activities related to defense responses are weakened in logs because a supply of photosynthetic carbohydrates is required to maintain quantitative disease resistance (23). In addition, the mortality of $Q$. crispula and $Q$. serrata by the artificial inoculation of $R$. quercivora is influenced by the phenology of host trees $(25,35,37)$, which tends to depend on host physiology. In the present study, the sapwood discoloration widths of these trees differed between experiment 1 (conducted in 2012) and experiment 2 (conducted in 2013), even though the discoloration widths of $Q$. glauca remained similar. These results suggest that the susceptibility of $Q$. crispula and $Q$. serrata to $R$. quercivora infection is more influenced by the physiological status of host trees than that of $Q$. glauca.

In conclusion, the present study demonstrated that the sapwood of different Fagaceae species responds differently to the inoculation of low- and high-virulence isolates of $R$. quercivora. Some of the host-pathogen interactions based on sapwood discoloration corresponded to the levels of mortality in the field, but there were exceptions. In addition, host-pathogen interactions are likely to reflect taxonomic classification rather than the vessel arrangement in the xylem (Supplementary Table S1). The mortality of oak trees caused by the $P$. quercivorus $-R$. quercivora complex is often called Japanese oak wilt. However, colonization by $R$. quercivora is limited to a narrow range of the xylem (34), tangentially within a few millimeters and longitudinally up to $20 \mathrm{~cm}$ or less $(17,37)$, which differs from other wilt diseases associated with bark and ambrosia beetles, such as Dutch elm disease and laurel wilt. The pathogens of these diseases are invasive fungi, and can colonize the tree body systemically. The occurrence and severity of the disease mainly depends on the interaction between host resistance and pathogen virulence $(24,29)$. In contrast, $R$. quercivora and $P$. quercivorus are regarded as species native to Japan. Mass attack by $P$. quercivorus and the mass introduction of $R$. quercivora are required for tree death (9). Thus, the mortality of oak trees in Japan is likely to depend on both the interactions of host resistance-beetle aggressiveness and host resistance-fungal virulence (18). To determine what causes variation in the levels of mortality among tree species, and to estimate the risk of mass mortality in oak forests, further studies are required, focusing on host-beetle interactions, comparisons of populations with isolates of differing virulence, and the physiological status of host trees.

\section{Acknowledgments}

We thank the staff from the University Tokyo of Chiba, Chichibu, and Tanashi Forest for their support in preparing the logs that we used in the inoculation experiment; and Doi Sethup-Pui National Park, Thailand, Cibodas Botanical Garden, LIPI, Indonesia, and a logging site by HTX Phuong Thai Ltd., Vietnam, the locations where we collected fungal insolates, for their cooperation with this work. This research was supported by the JSPS Grants-in-aid for Scientific Research to N. Kamata (17405028, 20405027, and 23255011).

\section{Literature Cited}

1. Eskalen, A., Gonzalez, A., Wang, D. H., Twizeyimana, M., Mayorquin, J. S., and Lynch, S. C. 2012. First report of a Fusarium sp. and its vector tea shot hole borer (Euwallacea fornicatus) causing Fusarium dieback on avocado in California. Plant Dis. 96:1070. 
2. Fraedrich, S. W., Harrington, T. C., Rabaglia, R. J., Ulyshen, M. D., Mayfield, A. E., Hanula, J. L., Eickwort, J. M., and Miller, D. R. 2008. A fungal symbiont of the redbay ambrosia beetle causes a lethal wilt in redbay and other Lauraceae in the southeastern United States. Plant Dis. 92:215-224.

3. Freeman, S., Sharon, M., Maymon, M., Mendel, Z., Protasov, A., Aoki, T., Eskalen, A., and O'Donnell, K. 2013. Fusarium euwallaceae sp. nov.-A symbiotic fungus of Euwallacea sp., an invasive ambrosia beetle in Israel and California. Mycologia 105:1595-1606.

4. Ida, H., and Takahashi, S. 2010. Mass mortality of oak trees had already occurred at the Edo period. J. Jpn. For. Soc. 92:115-119. (In Japanese with English abstract)

5. Ito, S., and Yamada, T. 1998. Distribution and spread of mass mortality of oak trees. J. Jpn. For. Soc. 80:229-232. (In Japanese)

6. Kamata, N., Esaki, K., Kato, K., Igeta, Y., and Wada, K. 2002. Potential impact of global warming on deciduous oak dieback caused by ambrosia fungus Raffaelea sp. carried by ambrosia beetle Platypus quercivorus (Coleoptera: Platypodidae) in Japan. Bull. Entomol. Res. 92:119-126.

7. Kim, K. H., Choi ,Y. J., Seo, S. T., and Shin, H. D. 2009. Raffaelea quercusmongolicae sp. nov. associated with Platypus koryoensis on oak in Korea. Mycotaxon 110:189-197.

8. Kinuura, H. 2002. Relative dominance of the mold fungus, Raffaelea sp., in the mycangium and proventriculus in relation in adult stages of the oak platypodid beetle, Platypus quercivorus (Coleoptera; Platypodidae). J. For. Res. 7:7-12.

9. Kinuura, H., and Kobayashi, M. 2006. Death of Quercus crispula by inoculation with adult Platypus quercivorus (Coleoptera: Platypodidae). Appl. Entomol. Zool. 41:23-128.

10. Kobayashi, M., and Hagita, M. 2000. Process of mass mortality of oak trees and capture of Platypus quercivorus Murayama (Coleoptera: Platypoidae). Appl. For. Sci. 9:133-140. (In Japanese with English abstract)

11. Kobayashi, M., Nozaki, A., and Kinuura, H. 2004. Influence of sap on reproduction of Platypus quercivorus (Murayama) (Coleoptera: Platypodidae). Appl. For. Sci. 13:155-159. (In Japanese)

12. Kobayashi, M., and Ueda, A. 2005. Wilt disease of Fagaceae trees caused by Platypus quercivorus (Murayama) (Coleoptera: Platypodidae) and the associated fungus: Aim is to clarify the damage factor. J. Jpn. For. Soc. 87:435-450. (In Japanese with English abstract)

13. Kubono, T., and Ito, S. 2002. Raffaelea quercivora sp. nov. associated with mass mortality of Japanese oak, and the ambrosia beetle (Platypus quercivorus). Mycoscience 43:255-260.

14. Kuroda, K. 2001. Responses of Quercus sapwood to infection with the pathogenic fungus of a new wilt disease vectored by the ambrosia beetle Platypus quercivorus. J. Wood Sci. 47:425-429.

15. Kuroda, K., and Yamada, T. 1996. Discoloration of sapwood and blockage of xylem sap ascent in the trunks of wilting Ouercus spp. following attack by Platypus quercivorus. J. Jpn. For. Soc. 78:84-88. (In Japanese with English abstract)

16. Kusumoto, D., Masuya, H., Hirao, T., Goto, H., Hamaguchi, K., Chou, W.-I, Suasa-ard, W., Buranapanichpan, S., Uraichuen, S., Kern-asa, O., Sanguansub, S., Panmongkol, A., Quang, T. P., Kahono, S., Julistiono, H., and Kamata, N. 2013. Discoloration induced by Raffaelea quercivora isolates in Quercus serrata logs and its relation to phylogeny: A comparison among isolates with and without the Japanese oak wilt incidence including outside of Japan. J. For. Res. 19:404-410.

17. Kusumoto, D., Masuya, H., Ohmura, K., and Kamata, N. 2012. Virulence of Raffaelea quercivora isolates inoculated into Quercus serrata logs and $Q$. crispula saplings. J. For. Res. 17:393-396.

18. Masuya, H., and Yamaoka, Y. 2012. The relationships between the beetle's ecology and the pathogenicity of their associated fungi. J. Jpn. For. Soc.
94:316-325. (In Japanese with English abstract)

19. Matsumoto, K. 1955. An outbreak of Platypus quercivorus and its control. For. Pests 4:74-75. (In Japanese)

20. Murata, M., Matsuda, Y., Yamada, T., and Ito, S. 2009. Differential spread of discoloured and non-conductive sapwood among four Fagaceae species inoculated with Raffaelea quercivora. For. Pathol. 39:193-199.

21. Murata, M., Yamada, T., Matsuda, Y., and Ito, S. 2007. Discoloured and non-conductive sapwood among six Fagaceae species inoculated with Raffaelea quercivora. For. Pathol. 37:73-79.

22. Nishigaki, S., Inoue, M., and Nishimura, N. 1998. The relationship between the number of Platypus quercivorus and the water content of wood and mass mortality of oak trees. Appl. For. Sci. 7:117-120. (In Japanese with English summary)

23. Pennypacker, B. W. 2000. Differential impact of carbon assimilation on the expression of quantitative and qualitative resistance in alfalfa (Medicago sativa). Physiol. Mol. Plant Pathol. 57:87-93.

24. Ploetz, R. C., Pérez-Martínez, J. M., Smith, J. A., Hughes, M., Dreaden, T. J., Inch, S. A., and Fu, Y. 2012. Responses of avocado to laurel wilt, caused by Raffaelea lauricola. Plant Pathol. 61:801-808

25. Saito, S., Nakamura, H., Miura, N., Mikawa, K., and Onose, K. 2001. Process of mass oak mortality and the relation to Platypus quercivorus and its specific fungus. J. Jpn. For. Sci. 83:58-61. (In Japanese with English abstract)

26. Saito, S., and Shibata, M. 2012. The forest structure and tree death rate of forest stands damaged by Japanese oak wilt in Yamagata Prefecture. J. Jpn For. Soc. 94:223-228. (In Japanese with English abstract)

27. Sekine, T., Takahashi, H., Imai, M., Nakanishi, J., Kawatsu, Y., Ida, N., Yamamoto, M., and Wakabayashi, D. 2011. Japanese oak wilt in urban forest: Damage situation at Kyoto Gyoen National Garden. J. Jpn. For. Soc 93:239-243. (In Japanese with English abstract)

28. Shiomi, S., and Osaki, S. 1997. Mass mortality of Quercus serrata and $Q$ mongolica in Hyogo Prefecture. Appl. For. Sci. 6:197-198. (In Japanese)

29. Smalley, E. B., and Guries, R. P. 1993. Breeding elms for resistance to Dutch elm disease. Annu. Rev. Phytopathol. 31:325-352.

30. Sone, K., Ushijima, T., Mori, T., Ide, M., and Umata, H. 1995. Incidence and spatial distribution of trees infested by the oak borer, Platypus quercivorus (Murayama) (Coleoptera: Platypodidae), in a stand. Bull. Kagoshima Univ. For. 23:11-22. (In Japanese with English summary)

31. Sperry, J. S., Nichols, K. L., Sullivan, J. E. M., and Eastlack, S. E. 1994. Xylem embolism in ring-porous, diffuse-porous, and coniferous trees of northern Utah and interior Alaska. Ecology 75:1736-1752.

32. Sueyoshi, M. 1990. The incidence of broadleaved trees attacked by Platypus quercivorus (Coleoptera: Platypodidae) (1). For. Pests 39:58-61. (In Japanese)

33. Sueyoshi, M. 1990. The incidence of broadleaved trees attacked by Platypus quercivorus (Coleoptera: Platypodidae) (2). For. Pests 39:242-245. (In Japanese)

34. Takahashi, Y., Matsushita, N., and Hogetsu, T. 2010. Spatial distribution of Raffaelea quercivora in xylem of naturally infested and inoculated oak trees. Phytopathology 100:747-755.

35. Torii, M., Matsuda, Y., Murata, M., and Ito, S. 2011. Spatial distribution of Raffaelea quercivora hyphae in transverse sections of seedlings of two Japanese oaks species. For. Pathol. 41:293- 298.

36. Yamada, T. 1998. Contribution of active defense responses in the limitation of fungal spread in the sapwood of living sugi (Cryptomeria japonica) tree. J. For. Res. 3:103-109.

37. Yamato, M., Yamada, T., and Suzuki, K. 2001. Wilt of oaks - blockage of xylem sap ascent. Bull. Tokyo Univ. For. 106:69- 76. (In Japanese with English summary) 